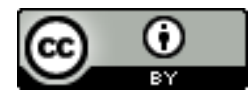

Esta obra está sob o direito de Licença Creative Commons Atribuição 4.0 Internacional.

\title{
CONTRIBUIÇÕES DA PSICOLOGIA DA EDUCAÇÃO PARA A FORMAÇÃO INTEGRAL DO TRABALHADOR
}

\author{
Jucilene Antero da Rocha Santos ${ }^{1}$ \\ Ivaci Bonfim Pinheiro ${ }^{2}$ \\ Joselito Araújo Silva ${ }^{3}$ \\ Eliane Reis Neves da Silva ${ }^{4}$ \\ Luciano Canuto Jacinto ${ }^{5}$ \\ Maria das Graças da Silva ${ }^{6}$
}

\section{RESUMO}

Este trabalho visa estudar as possíveis contribuições da Psicologia da Educação para a Formação Integral do Trabalhador. Para tanto, buscou-se conhecer os conceitos de trabalho e, entender como se dá a atual formação do trabalhador na sociedade capitalista brasileira, além de definir a formação humana integral e a relação entre ela e a Psicologia da Educação. A pesquisa foi realizada através de um estudo bibliográfico. O estudo realizado possibilitou a percepção de que o trabalho concreto é condição da existência humana, e o trabalho abstrato, alienado é a base para existência do capitalismo. Assim, como na sociedade capitalista a formação do trabalhador é basicamente a formação da força de trabalho de que necessita o mercado de trabalho, a formação integral somente será possível em sua plenitude em outra forma de sociabilidade, pois nesta tudo está submetido ao julgo do capital, porém é possível com auxílio da Psicologia da educação que seja empreendida uma educação que conduza a formação crítica dos indivíduos, e estes poderão lutar pela transformação da sociedade em que vivem.

Palavras-chave: Evasão escolar. Estudante. Ensino básico.

Submetido em junho de 2020 e aceito em setembro de 2020.

\section{RESUMEN}

Este trabajo tiene como objetivo estudiar las posibles contribuciones de la Psicología de la Educación para el Trabajador Formación Integral. Por lo tanto, hemos tratado de conocer los conceptos de trabajo y la comprensión de cómo la formación de los trabajadores en la sociedad

\footnotetext{
1 Jucilene-antero@hotmail.com

2 ivaci18@outlook.com

3 joselitoaraujo947@gmail.com

4 elianereis@uol.com.br

5 lucianocanutojacinto11@gmail.com

6 gracahej@hotmail.com
} 
capitalista actual brasileña, y para definir el desarrollo humano integral y la relación entre ésta y la Psicología de la Educación. La encuesta se realizó a través de un estudio de la literatura. El estudio dio lugar a la percepción de que el trabajo concreto es una condición de la existencia humana, y el trabajo abstracto, alienado es la base para la existencia del capitalismo. Por lo tanto, al igual que en la sociedad capitalista la formación del trabajador es básicamente la formación de la fuerza de trabajo que necesita el mercado laboral, la formación completa será sólo sea posible en su plenitud en otra forma de sociabilidad, porque todo esto está sujeto al yugo del capital Pero es posible con la ayuda de la psicología de la educación que la educación se lleva a cabo dando lugar a la formación crítica de individuos, y pueden luchar por la transformación de la sociedad en la que viven.

Palabras clave: Trabajo. La sociedade. Capitalista. Psicología de la Educación. Formación Integral. 


\section{INTRODUÇÃO}

O presente trabalho trata das contribuições da Psicologia da Educação para a Formação Integral do Trabalhador. A pesquisa sobre o tema partiu da necessidade de conhecer mais sobre como a Psicologia da Educação pode efetivamente auxiliar para a formação integral do trabalhador. Compreendendo-se que a formação do trabalhador atual é, em sua grande maioria, a formação escolar básica, e/ou técnica através de cursos profissionalizantes que são de curta duração e visam à inserção rápida do trabalhador no mercado de trabalho, enfatizando a formação de técnicos, necessário se faz que se descubram formas de garantir uma formação mais humana e crítica que os proporcione a compreensão do mundo à sua volta.

A pesquisa realizada objetivou compreender os conceitos de trabalho e, entender como se dá a atual formação do trabalhador na sociedade capitalista brasileira, além de definir a formação humana integral, e sua relação com a Psicologia da Educação. A mesma, foi empreendida com a utilização de uma abordagem qualitativa, por meio de pesquisa bibliográfica, que permitiu entender o objeto de estudo em questão, com procedimentos que envolveram a leitura e fichamento do material pesquisado, tendo como base estudos teóricos já realizados sobre a temática.

Para expor os resultados da pesquisa o presente texto se estrutura em três seções. A primeira traz o conceito de trabalho e está dividida em duas subseções, uma define trabalho concreto e a outra o trabalho abstrato; a segunda seção aborda a formação do trabalhador na atual sociedade capitalista, e apresenta uma subseção que fala do ensino técnico e profissionalizante no Brasil; enquanto a terceira seção ressalta a questão da formação integral do trabalhador, com uma subseção que trata da relação entre Psicologia da Educação e Formação Integral.

De um modo geral este trabalho longe de apresentar conclusões definitivas sobre a temática pesquisada vem suscitar a necessidade de maiores investigações sobre a mesma, uma vez que a educação é um direito fundamental de todos os seres humanos e dada a necessidade de uma sociedade mais justa e igualitária é preciso que tenhamos garantido este direito e com qualidade, de forma que o mesmo possibilite uma formação crítica, verdadeiramente humana e integral para todos. 
Rev. Científica Evidência, Maceió, v. 3, n.1, p. 12-28, jul/set, 2020

\section{METODOLOGIA}

Trata-se de uma revisão de literatura tradicional, não sistemática, descritiva, de

\section{RESULTADOS E DISCUSSÕES}

\section{Conceituando trabalho}

O trabalho é uma atividade exclusivamente humana, o que significa dizer que apenas o ser humano desenvolve trabalho. Esta é uma categoria social e é considerada como a mais importante do ser social, de tal forma que, é o tipo de trabalho ou a forma como se dá a divisão social do trabalho que determinam o tipo de sociedade humana estabelecida. Foi a capacidade de realizar trabalho que possibilitou a sobrevivência humana e o desenvolvimento social através dos tempos. Toda a história da humanidade está marcada pelo trabalho, de maneira que é impossível a existência humana sem o trabalho.

O conceito de trabalho, na perspectiva marxista pode ser entendido de duas maneiras: como trabalho em si, ou trabalho concreto, categoria fundante do ser social, que se apresenta como condição para a sobrevivência do ser humano, não podendo em hipótese alguma ser eliminado; e sob a vigência do sistema do capital, como trabalho abstrato, alienado, condição necessária à perpetuação do sistema de exploração do homem pelo homem para natureza qualitativa, com análise de conteúdo de livros e documentos adquiridos em bibliotecas físicas e virtuais.

garantir a acumulação e reprodução do modo de produção capitalista.

\section{Trabalho concreto}

O trabalho concreto como chamam os marxistas, é o trabalho que cria valor de uso, ou seja, é a atividade humana de transformação da natureza para satisfazer a sua própria necessidade. "O produto [do trabalho] é um valor de uso, um material da natureza adaptado às necessidades humanas através da mudança de forma" (MARX, 2011, p. 214). Neste processo de transformação da natureza o ser humano também se transforma, à medida que vai desenvolvendo suas capacidades cerebrais de pensar e de aprender e passam a ensinar aos seus pares, em sociedade, os conhecimentos adquiridos.

O trabalho concreto é considerado como a categoria que funda o ser social, por ser esta forma de trabalho que criou o mundo dos homens, e que possibilitou ao ser humano passar de ser natural a ser social. Visto desta forma o trabalho é "condição necessária do intercâmbio material entre o homem e a natureza; é condição natural eterna da vida humana, sem depender, portanto, de qualquer forma dessa vida, sendo antes comum a toda as 
suas formas socais" (MARX, 2011, p. 218).

Assim não é possível que exista sociabilidade humana sem o trabalho.

De acordo com Silva, Mata e Klein (2010), para sobrevivência da espécie humana, que diferentemente dos demais animais não conta com instrumentos de sobrevivência como

garras, prezas, velocidade ou força, o ser humano utilizou as vantagens que possuía como o avantajado desenvolvimento do cérebro e suas patas dianteiras diferenciadas que o tornavam adaptáveis ao trabalho. Devido necessidades fundamentais a vida, como abrigo, alimentação e reprodução, o homem precisou transformar a natureza de forma a satisfazê-las, e o fez através de instrumentos que construiu com elementos da própria natureza para ampliar as suas capacidades. Esta interação com a natureza, a atividade cooperada e a divisão social do trabalho possibilitaram a sobrevivência do ser humano.

Nesta perspectiva a função do trabalho é a criação de valores de uso, ou seja, produzir para satisfazer as necessidades humanas. E assim sendo, é essencial para a sobrevivência humana independentemente do tipo de sociabilidade que se estabeleça ao longo da história, de maneira que mesmo que mudem as formas de produzir, pois é a forma de produção que define o tipo de sociedade, o trabalho enquanto intercâmbio material entre 0 homem e a natureza sempre existiu e sempre irá existir.

\section{Trabalho abstrato}

Com a instituição da propriedade privada e surgimento do modo de produção capitalista passa a existir outra categoria de trabalho, qual seja o trabalho abstrato. $\mathrm{O}$ mesmo, tem como pressuposto o trabalho assalariado e a criação de valor de troca. Para Tonet (2010) este trabalho que é realizado a partir da compra e venda da força de trabalho é o ato fundante da sociabilidade do capital. Pode-se perceber que enquanto o trabalho concreto funda o ser social o trabalho abstrato funda a sociedade capitalista.

Conforme Frigotto (2009) na sociedade capitalista o trabalho assume centralidade como uma mercadoria especial a ser negociada no mercado que é a força de trabalho. Esta é vendida pelos trabalhadores, por ser o único meio de que dispõem para negociar com os capitalistas detentores dos meios de produção, que em troca do trabalho realizado oferece uma remuneração financeira. Esta remuneração é o salário de que o trabalhador necessita para garantir a sua sobrevivência e da sua família.

Na análise de Marx (2011), a força de trabalho é uma mercadoria da classe trabalhadora que é consumida pelo capitalista, de maneira que o processo de 
Rev. Científica Evidência, Maceió, v. 3, n.1, p. 12-28, jul/set, 2020

trabalho apresenta dois fenômenos característicos: o trabalhador executa seu trabalho "sob o controle do capitalista a quem pertence seu trabalho" (MARX, 2011, p.219), e o produto do trabalho é propriedade do capitalista, e não do trabalhador que o produziu. Assim, este trabalho se torna alienado à medida que o trabalhador não se reconhece no produto do seu trabalho, este lhe é alheio, não lhe pertence, além disso, com a intensificação da divisão social do trabalho cada trabalhador realiza apenas uma parte mínima do processo de produção de um produto.

Marx (2011, p.220) estabelece os objetivos da produção, quais sejam: produzir valor de uso, que tenha valor de troca, ou seja, mercadorias; e, esta mercadoria deve ter um valor mais elevado do que as mercadorias que ele utilizou para fabricá-la, como meios de produção e força de trabalho, produzindo assim um valor excedente, que é a mais valia. A mais valia é derivada da exploração da força de trabalho. A manutenção da força de trabalho custa menos tempo que a jornada inteira, de modo que o que ela produz numa jornada é superior ao seu valor de troca, daí é que nasce o lucro do capitalista.

O trabalho abstrato é, portanto, “a redução da capacidade produtiva humana a uma mercadoria, a força de trabalho, cujo preço é o salário.” (LESSA, 2012, p.28).
Com isto entende-se que todo trabalho assalariado é trabalho abstrato, e é realizado sob o julgo do capital, mediante a exploração do trabalhador, que é em suma a garantia da reprodução do sistema capitalista que necessita de lucros e acumulação para poder se perpetuar enquanto sistema de produção e, consequentemente, forma de organização social.

Desta maneira que o trabalho abstrato, que é em suma o trabalho assalariado, pode vir a desaparecer, por ser uma particularidade da sociedade e do modo de produção capitalista, porém o trabalho concreto jamais poderá deixar de existir, porque ele é condição para a existência da sociabilidade humana, assumindo esta qualquer forma que seja.

\section{Formação do trabalhador na atual sociedade capitalista}

A sociedade capitalista estabelece relação entre educação e trabalho à medida que a educação objetiva a formação dos trabalhadores para que atuem de forma satisfatória no mercado de trabalho. Como a força de trabalho é tida como uma mercadoria para o capital, sua formação tende a ser vista como um investimento para o aumento da produtividade deste. E ao mesmo tempo, a educação é considerada pelos trabalhadores como uma forma de garantir a possibilidade de ingresso e 
Rev. Científica Evidência, Maceió, v. 3, n.1, p. 12-28, jul/set, 2020

permanência no mercado de trabalho cada vez mais competitivo.

$\mathrm{Na}$ sociedade capitalista "a função essencial da educação é a de preparar os indivíduos para o trabalho" (TONET, 2007, p.10), assim ela é considerada eficaz quando prepara adequadamente os indivíduos para o exercício profissional, pois nesta sociabilidade o indivíduo vale enquanto força de trabalho para o capital.

Porém, como temos duas classes sociais antagônicas, capitalistas e trabalhadores, a educação escolar que se desenvolve, principalmente em nossa realidade brasileira, tem dois objetivos distintos, que é a formação das elites dominantes e a formação dos trabalhadores, de maneira que, se desenvolveu e ainda é vigente em nosso país, um sistema de educação dual, como enfatiza Romanelli (2010), assim, de um lado temos o ensino destinado às elites, ou classe dominante, com uma educação superior que prepara para carreiras liberais, enquanto de outro lado o ensino dispensado aos trabalhadores é aquele que se reduz a preparação para o mercado de trabalho e em um curto espaço de tempo.

Desta maneira temos no Brasil um ensino destinado aos trabalhadores que é constituído pela educação básica e técnico profissionalizante, de tal forma que o ensino médio em muitas instituições é também técnico e prepara os indivíduos para o ingresso no mercado de trabalho.

\section{Ensino técnico e profissionalizante}

De acordo com o art. 39 da Lei de Diretrizes e Bases da Educação Nacional (LDB), Lei $n^{\circ}$ 9.394/96, a educação profissional é prevista em articulação com o ensino regular, seja nos níveis fundamental, médio ou superior. Desta maneira, são estabelecidos três níveis de educação profissional, que conforme Coutinho (2007) são: o nível básico que busca qualificar e requalificar os trabalhadores preparando-os para ocupações demandadas pelo mercado de trabalho independentemente $\mathrm{da}$ escolaridade dos mesmos; o nível técnico que visa a profissionalização de nível médio, que pode ser realizado tanto concomitante como sucessivamente; e o nível tecnológico que é correspondente ao nível superior, e se destina à formação técnico-científica do conhecimento.

Além desses três níveis ainda existem os cursos complementares de especialização, aperfeiçoamento e atualização que também fazem parte da educação profissional. Na visão de Santos (et.al, 2009), independente do nível em que os cursos são oferecidos, todos têm a função de construir uma subjetividade inerente ao trabalho social necessário no referido momento histórico. De maneira que, atualmente as exigências da educação 
profissional é que ela atenda aos objetivos do mercado de trabalho para viabilizar o processo de globalização. A lógica deste tipo de educação é formar a força de trabalho de acordo com as demandas do mercado de trabalho, e com as transformações sofridas no mesmo contemporaneamente. Com a internacionalização dos processos produtivos, e dos mercados financeiro e comercial, a qualificação dos trabalhadores, em especial dos setores em que se encontram a maioria da população, passa a ser de responsabilidade dos governos como uma condição para participar do processo de globalização do capital.

Neste sentido, de acordo com Santos (et. al., 2009), no Brasil, a maior oferta de cursos de curta duração, que visam preparar para atividades que não requerem escolaridade acima do ensino fundamental, é feita pelo Plano Nacional de Qualificação Profissional e Social, coordenado pelo Ministério do Trabalho e Emprego, com financiamento do Fundo de Amparo ao Trabalhador (FAT), e executado por entidades privadas selecionadas pelas Secretarias Estaduais de Trabalho ou suas equivalentes.

Almeida (2012, p. 4114) apresenta a constatação de que,

“[...] a escola e a educação, de forma mais ampla no Brasil, historicamente vem se organizando e se desenvolvendo com vistas ao atendimento das necessidades do setor produtivo em vigor, manifestando em diferentes contextos características semelhantes às desenvolvidas pelo setor produtivo."

Isto se processa de tal forma que quando vigorava o modelo de produção taylorista/fordista, em que se produzia em massa e as atividades desenvolvidas pelos trabalhadores eram repetitivas, a educação técnica tinha este caráter repetitivo, e com o incremento do modelo Toyotista, cuja produção está vinculada a demanda e os trabalhadores desenvolvem diversas atividades e em equipe, a educação tende a ser mais flexível, uma vez que o trabalhador polivalente terá que utilizar mais suas capacidades cognitivas e não apenas motoras como se verificava no modelo de produção anterior.

Com todas as mudanças evidenciadas no mercado de trabalho, este passou a demandar um trabalhador cada vez mais capacitado, um trabalhador polivalente, multifuncional e criativo, com uma postura ativa, capaz de realizar diferentes atividades, e de se adaptar a situações novas de trabalho. Coutinho (2007) discorre a respeito do discurso da empregabilidade, no qual se propaga que, quanto maior o grau de escolaridade e de capacitação/profissionalização trabalhador poderia ter assegurado 
Rev. Científica Evidência, Maceió, v. 3, n.1, p. 12-28, jul/set, 2020

melhores ganhos e maios chance de inserção no mercado de trabalho.

Porém como o sistema do capital é contraditório, não se criam postos de trabalho suficientes para absorver toda esta força de trabalho capacitada, isto só aumenta o número de pessoas capacitadas e faz cair os salários daqueles que conseguem se inserir no mercado de trabalho. Outra contradição do sistema do capital que ao tempo em que demanda trabalhadores com alto grau de capacitação, mantém trabalhadores analfabetos e com pouca escolarização que, vivendo no mesmo sistema não precisam ler, pois o mercado de trabalho absorve esta força de trabalho pouco capacitada para realizar certas atividades que não necessitam de capacitação.

Isto possibilita entender o problema do analfabetismo que ainda é um problema em nosso país e, mais grave na região nordeste do Brasil. Dentre os vários motivos, deste problema, Santos (2012) aponta um fator que leva a descrença dos nordestinos pela educação, segundo ele, como a região é a mais pobre do país e sua economia durante mais de quatro séculos ter sido agroexportadora, cujo trabalho se baseia em atividades que não exigem capacitação profissional, e por este trabalho, que era o único disponível, não lhes permitir uma melhoria nas condições de vida, as pessoas não viam a necessidade de estudar e preferiam ingressar precocemente no mercado de trabalho.

Entende-se, portanto, a necessidade de erradicarmos o analfabetismo em todo o país, porém a educação seja ela regular ou profissionalizante tem como objetivo a formação para o mercado de trabalho, e como assinala Santos (et.al, 2009) os cursos profissionalizantes têm um caráter tecnicista, o que não possibilita aos sujeitos desenvolver mais profundamente suas Funções Psicológicas Superiores, ficando assim impossibilitados de conhecer efetivamente a realidade em que vive, daí a necessidade urgente de uma educação crítica, de uma formação do ser humano realmente plena, integral.

\section{A formação integral do trabalhador}

A formação do trabalhador deve extrapolar o caráter técnico e ser uma formação que realmente lhe permita conhecer e compreender a realidade em que vive e, que lhe possibilite se reconhecer enquanto sujeito histórico e construtor da história da humanidade. Para tanto a educação oferecida aos trabalhadores deve ser uma educação crítica, para que possam se desenvolver de forma integral, para que possam contribuir efetivamente para a transformação da sociedade, e a construção de uma sociabilidade qualitativamente melhor. 
Todavia, é necessário que se desenvolva uma educação voltada não apenas para a formação profissional, pois antes de qualquer coisa o trabalhador é um ser humano e precisa de uma formação que lhe permita o desenvolvimento integral enquanto tal. Conforme Santos (et.al., 2009, s.p.) "para contemplar o desenvolvimento psicossocial e não apenas o mercado de trabalho, a formação profissional deve zelar pela preparação de sujeitos cada vez mais humanos: sujeitos que aprendam e tornem suas as capacidades sociais de agir, se emocionar, pensar". Afinal a todo ser humano deve ser possibilitadas condições de um bom desenvolvimento físico, mental, afetivo e social.

No dizer de Silva, Mata e Klein (2010, p. 116), “As ações intencionais desenvolvidas junto ao aluno trabalhador no processo de escolarização devem mobilizar as suas potencialidades, aprimorar o seu conhecimento da realidade e oportunizar o alcance da consciência crítica instruída de si e do mundo". É preciso que seja oferecida uma formação que possibilite ao trabalhador entender a realidade em que está inserido, para que possa agir nesta realidade de maneira consciente com a finalidade de transformá-la, tendo a certeza de que são os próprios seres humanos que constroem a história, e que eles são os protagonistas que podem decidir os rumos que esta história irá tomar.
Tonet (2012), apoiado em Marx, afirma que um indivíduo para se tornar membro do gênero humano necessita se apropriar do patrimônio material e espiritual acumulado pela humanidade, e tudo que servir de obstáculo a essa apropriação impede o desenvolvimento do indivíduo como ser humano integral. Em nossa sociedade, como nos lembra Tonet (2012), é proclamado o direito a uma formação integral, porém temos uma maioria que é excluída do acesso aos meios que a possibilitam, e os que conseguem ter acesso à formação se privilegiam os aspectos espirituais, que incluem formação moral, artística, cultural, intelectual, e o acesso aos bens materiais não acontece.

Seguindo com seus argumentos Tonet (2012), postula que na sociedade capitalista a formação chamada de integral, que em tese inclui a preparação para o trabalho, na realidade não é mais que a formação de mão-de-obra para o capital. Então, defende que uma verdadeira formação integral é impossível na sociabilidade regida pelo capital, e que ela somente será possível com a superação do sistema capitalista. Isto porque este sistema é extremamente contraditório e não consegue manter-se sem desigualdades de classes, por isso não garante a formação humana integral, uma vez que esta pressupõe o acesso a todos os bens que a humanidade já produziu, e estes bens não se 
resume ao conhecimento científico, mas também aos bens materiais, sendo que estes últimos não são acessíveis a maioria da classe trabalhadora.

Uma educação integral, deve formar:

[...] indivíduos capazes de pensar com lógica, de ter autonomia moral; indivíduos que se tornem cidadãos capazes de contribuir para as transformações sociais, culturais, científicas e tecnológicas que garantam a paz, o progresso, uma vida saudável e a preservação do nosso planeta. Portanto, pessoas criativas, participativas e críticas. (TONET, 2012, p. 80-1).

Percebe-se que uma formação mais crítica poderá contribuir para a construção de uma sociedade qualitativamente melhor, sem desigualdades sociais. Necessita, porém como o próprio Tonet (2012) nos adverte, de uma educação efetivamente integral, que somente será possível em uma sociedade essencialmente diferente, uma vez que na sociedade capitalista isto não é possível. No entanto apresenta as atividades educativas inseridas na luta pela transformação radical da sociedade, como alternativas de contribuição para uma formação integral, a medida que poderão formar indivíduos comprometidos com a construção da sociabilidade comunista na qual a educação integral poderá se realizar.

Assim, para que se tenha a formação humana integral deve-se assumir o compromisso com a luta pela construção de outra forma de sociedade, sem desigualdades sociais a que Tonet (2012) denomina comunista. Para tanto, este autor defende que é preciso: saber o que significa uma sociedade plenamente emancipada que é o fim maior que se quer atingir; conhecer a realidade social concreta, incluindo a história da humanidade e a sociedade capitalista; além de desenvolver atividades que incentivem as pessoas a participar das lutas sociais articuladas à transformação radical da sociedade.

Este seria o primeiro passo para tornar possível a construção de uma educação capaz de formar integralmente o ser humano. Para tanto, é necessário que haja um real compromisso de todos os que atuam na educação com um projeto de sociedade radicalmente diferente, para que possam desenvolver atividades que levem os indivíduos a se tornarem pessoas críticas, e conscientes de seu papel enquanto partícipes do processo de transformação da sociedade. E isto será viável com a ajuda de estudos como os que são desenvolvidos pela psicologia da educação, que visam contribuir para um melhor desempenho com relação ao desenvolvimento e aprendizagem humana. 
Rev. Científica Evidência, Maceió, v. 3, n.1, p. 12-28, jul/set, 2020

Psicologia da educação e formação integral

A psicologia da educação pode ser entendida como um ramo da psicologia que aplica os estudos desta à educação. A Psicologia enquanto ciência, através de suas teorias desenvolvidas a partir da investigação do ser humano, seu lado cognitivo, e o funcionamento de sua mente, auxilia a educação a entender como se processa o desenvolvimento e a aprendizagem humana, e assim pode contribuir para a resolução de problemas relacionados à aprendizagem dos educandos.

Como a educação tem o papel de formar o ser humano para viver e atuar na sociedade, a formação que oferece se concebe de acordo com o tipo de sociedade que se vive ou que se deseja. Porém há algo indispensável na vida do ser social que é o trabalho, pois sem o trabalho ele não pode existir. No entanto, o ser social precisa desenvolver os conhecimentos adquiridos em sua relação com a natureza para produção de bens que satisfaçam as suas necessidades, ou seja, nas atividades de trabalho. E este desenvolvimento se dá através da interação com outros indivíduos através da educação.

A linguagem desempenha um papel importantíssimo neste processo de desenvolvimento humano. Para Silva, Mata e Klein (2010, p. 107), “a linguagem potencializa as funções psíquicas e se torna no decorrer do desenvolvimento do gênero humano um instrumento psicológico que engendra mudanças substanciais na condição psíquica do homem." Afinal a linguagem possibilitou ao ser humano ensinar às gerações mais jovens os conhecimentos das técnicas e das atividades que já desenvolveram e estes podiam a partir da base que recebiam de seus antepassados desenvolvê-las e criar novas técnicas, até chegar ao nível de desenvolvimento que temos hoje.

No que tange a relação entre a psicologia e a educação, em seu texto intitulado Das relações entre educação e psicologia na perspectiva de uma educadora, Almeida (2012), do alto dos seus cinquenta anos de carreira na educação afirma que a psicologia pode ajudar a enfrentar os problemas concretos do cotidiano escolar, e que pode contribuir para termos melhores educadores que trabalhem para um ensino que promova a igualdade e equidade de oportunidades para todos. A autora acredita que a dificuldade atual com relação a psicologia da educação é priorizar o que pode ser mais útil para realização de um trabalho de qualidade, diferentemente de quando iniciou a sua carreira cuja dificuldade era de encontrar obras de psicólogos traduzidas para o português que pudessem ser usadas para fundamentar a ação educativa. 
Almeida (2012) afirma que, a relação Psicologia e Educação foi, e continua sendo, uma relação complementar e construtiva. "As duas, numa relação dialética, se alimentam reciprocamente, oferecendo recursos uma à outra, para melhor compreensão do fenômeno educativo e de nós mesmos." (ALMEIDA, 2012, p.347). Daí a importância da psicologia da educação para auxiliar no desenvolvimento de uma educação voltada para a formação do ser

humano integral, afinal o ser humano não se resume a sua força de trabalho, portanto ele precisa desenvolver suas funções psíquicas e físicas que lhe permitam agir conscientemente sobre o mundo.

Vieira, Assis e Campos (2013, p. 399) consideram que a psicologia "vem favorecendo educação uma contribuição substancial na investigação dos processos de ensino e aprendizagem, proporcionando a oportunidade de reflexão sobre a eficácia das práticas educativas". Para tanto é preciso que as teorias estudadas no campo da psicologia sejam levadas para a prática na sala de aula como subsídio para a realização de uma prática pedagógica que realmente favoreça o desenvolvimento e aprendizagem dos alunos.

No ensino de psicologia para educadores de acordo com Vieira, Assis e Campos (2013) existem dois paradigmas norteadores: o racional-técnico e o crítico- reflexivo. Enquanto o primeiro implica em aprender inicialmente a teoria para em seguida aplicar o conhecimento aprendido na prática; o segundo, que leva em consideração a complexidade da situação educativa e o contexto social no qual esta se insere, considera impossível a aplicação integral e linear de uma única teoria na prática pedagógica.

As autoras defendem o segundo paradigma por considerarem que os professores devem ser críticos e, ter condições de refletir sobre suas práticas à luz dos conhecimentos adquiridos no campo da psicologia. Desta forma:

[...] o ensino de psicologia nas licenciaturas deve, então, ser encaminhado de forma a entender o ser humano como pessoa, uma complexidade dotada de dimensões social, cultural, biológica, econômica, política, afetiva, ideológica, histórica e outras. [...] necessitam que seu caráter teórico estabeleça diálogos mais efetivos com a realidade em suas inúmeras facetas, favorecendo assim aos alunos/futuros professores refletir e agir em seus espaços educativos buscando as transformações necessárias. (VIEIRA, ASSIS e CAMPOS, 2013, P. 400).

Considera-se acertada a opção teórica das autoras, e seus argumentos, já que é fundamental que o professor compreenda a integralidade do sujeito, e que esta é formada por várias dimensões, para que assim desenvolva um trabalho que 
possibilite a formação integral do mesmo. É preciso que os professores tomem consciência de que a educação escolar não acontece dissociada da sociedade na qual é desenvolvida, e que esta sociedade, por sua vez, é formada de diferentes contextos sociais e culturais nos quais vivem pessoas também diferenciadas, e é necessário trabalhar para atender a todos, se a pretensão for a garantia do direito de todos à educação.

Tonus (2013) apresenta quatro concepções teóricas da psicologia da educação, quais sejam: o objetivismo cientificista, que parte do pressuposto de que o conhecimento é predeterminado nas estruturas internas do indivíduo, e fundamenta a escola tradicional; o subjetivismo, que propõe que a consciência é resultado de sensações subjetivas, e embasa o movimento da Escola Nova, esta que tinha como propósito que o aluno se autodesenvolva, tenha realização pessoal e liberdade na sociedade capitalista em ascensão; o interacionismo, desenvolvido por Piaget, parte do pressuposto de que o conhecimento é construído na ação do sujeito com o ambiente.

Estas três concepções, de acordo com Tonus (2013), concebem o fenômeno psíquico como natural, porém a psicologia sócio-histórica, defendida pela autora como a concepção mais apropriada para a educação, busca superar as limitações das demais e "concebe o homem como ser em constante movimento, que transforma sua realidade ao longo do tempo e é também por ela transformado (TONUS, 213, p. 274)". Desta maneira, entende-se que o fenômeno psíquico não é algo natural, e sim algo construído socialmente, o ser humano desenvolveu suas capacidades psicológicas a partir de sua vivência social.

De acordo com a autora citada, a Psicologia Sócio-histórica considera o conceito de condição humana em detrimento do conceito de natureza humana, uma vez que compreende o ser humano como um ser social que constrói a sua própria história. Note-se que, tanto na educação tradicional como na Escola Nova o homem é visto como um indivíduo que já nasceu com as características do seu psiquismo, por isto considera culpa do aluno a sua condição e fracasso escolar, pois concebe que ele já nasceu capaz ou incapaz de aprender, e como a educação é tida como isolada do contexto social e cultural dos sujeitos, estes fatores não podem ser considerados ao se analisar as dificuldades de aprendizagem dos alunos.

Como a psicologia da educação atualmente enquanto disciplina objetiva "preparar os futuros professores para compreenderem o desenvolvimento „,normal ${ }^{\text {ee }}$ da criança e estarem atentos ao que possa ser indicativo de ,desvio de comportamento $^{\text {ee" }}$ (TONUS, 2013, p. 275), 
Rev. Científica Evidência, Maceió, v. 3, n.1, p. 12-28, jul/set, 2020

o que implica em apontar a própria criança como responsável pelas suas dificuldades, com base no paradigma subjetivista e junto com a ideologia dominante, não tem contribuído, para a verdadeira emancipação humana, vem apenas formando força de trabalho adequada para o mercado de trabalho capitalista.

Por isto, Tonus (2013), defende ser a Psicologia Sócio-histórica a concepção teórica que oferece condições para se pensar a educação escolar, por que ela enfatiza a importância da mediação social para a

\section{CONSIDERAÇÕES FINAIS}

A pesquisa realizada para produção deste texto buscou estudar as possíveis contribuições da Psicologia da Educação para a formação integral do trabalhador. Para tanto foi necessário, conhecer os conceitos de trabalho, entender como se dá a atual formação do trabalhador na sociedade capitalista brasileira, além de definir a formação humana integral, bem como estabelecer a relação existente entre esta formação e a Psicologia da Educação.

$\mathrm{O}$ que se verificou ao longo dos estudos foi que, de fato a formação do trabalhador atual é uma formação voltada quase que exclusivamente para a capacitação de sua força de trabalho para o mercado de trabalho. De maneira que, estão sendo formados bons técnicos, de acordo com as demandas, porém a formação destes constituição do psiquismo e o impacto da educação escolar sobre o desenvolvimento efetivo-cognitivo, em outras palavras, para uma formação humana integral. Assim, é preciso considerar a importância da Psicologia Sócio-histórica para o desenvolvimento de uma educação escolar que realmente forme o ser humano integral, considerando-o em seu aspecto social, cultural, afetivo, cognitivo, enfim, considerando a integralidade do sujeito.

trabalhadores enquanto seres humanos fica muito a desejar.

Diante do exposto pode-se concluir que, sendo o trabalho concreto de suma importância para a existência humana, tendo sido o responsável pela sobrevivência humana ao possibilitar a produção dos bens necessários para atender as suas necessidades, é fato que a formação humana deve envolver o trabalho, e a capacitação para o mesmo. Porém não se pode perder de vista que todo trabalhador é um ser humano, formado de diversas dimensões, que devem ser levadas em consideração para que se efetive uma formação verdadeiramente humana e integral.

Com relação às contribuições da Psicologia da Educação para uma formação humana integral dos trabalhadores, o paradigma existente e que melhor condiz, 
para esta realização é o crítico-reflexivo, por considerar que não é apenas uma teoria que vai dar conta do processo educativo e dos problemas dele advindos, mas que é preciso o conhecimento de diversas teorias uma vez que o ser humano é composto por diversas dimensões e uma teoria apenas não dá conta de responder a todas elas.

Concebendo-se o ser humano como um ser social, cultural, afetivo, enfim, um ser de muitas facetas, a concepção teórica considerada mais apropriada para a efetivação da formação integral a concepção Sócio-Histórica, por que vê o ser humano como ser histórico e social, portanto sua constituição psíquica é tida como produto de seu desenvolvimento, e não uma mera condição natural, e com a

\section{REFERÊNCIAS}

ALMEIDA, C. S. de. A relação entre trabalho e educação no Brasil. IX Seminário Nacional de Estudos e Pesquisas "História, Sociedade e Educação no Brasil". Universidade Federal da Paraíba - João Pessoa - 31/07 a 03/08/2012 - Anais Eletrônicos - ISBN 978-85-

7745-551-5. Disponível em: <http://www.histedbr.fe.unicamp.br/acer_h istedbr/seminario/seminario9/PDFs/7.09.p df>. Acesso em: 21 fev. 2015.

ALMEIDA, L. R. de. Das relações entre educação e psicologia na perspectiva de uma educadora. Revista Semestral da Associação Brasileira de Psicologia Escolar e Educacional, SP. Volume 16, Número 2, Julho/Dezembro de 2012. p. 341-348. concepção de trabalho defendida aqui, qual seja, trabalho concreto, nota-se que o ser humano se desenvolveu psiquicamente à medida que utilizou seu cérebro avantajado e suas patas dianteiras diferenciadas e começou a utilizar os elementos da natureza para produzir o que necessitava para garantir a sua sobrevivência.

Assim, defende-se que uma formação humana integral é possível, para tanto é preciso que sejam empreendidas atividades que proporcionem a formação de indivíduos críticos e conscientes, capazes de analisar a realidade em que vivem e de contribuir para a construção de uma sociedade melhor, mais justa e igualitária.

BRASIL. Lei n ${ }^{\circ}$ 9.394, de 20 de dezembro de 1996. Estabelece as Diretrizes e bases da educação nacional. Diário Oficial da União. Brasília, DF, 20 dez. 1996.

Disponível

em:<http://portal.mec.gov.br/arquivos/pdf/ ldb.pdf $>$. Acesso em: 21 fev. 2015.

COUTINHO, A. R. Educação e Trabalho. In: SILVEIRA, Rosa Maria Godoy, et al.

Educação em Direitos Humanos:

Fundamentos teóricos-metodológicos. João Pessoa:

Editora Universitária. 2007, p. 373-396.

FRIGOTO, Gaudêncio. Escola e trabalho numa perspectiva histórica: contradições e 
controvérsias. Texto da conferência proferida na Faculdade de Psicologia e de Ciências da

Educação da Universidade de Lisboa, a 12 de fevereiro de 2009. Revista de Ciências da

Educação, 09, p. 129-136. Disponível em: $<$

http://www.gestaoescolar.diaadia.pr.gov.br /arquivos/File/sem_pedagogica/fev_2010/e scola_tr

abalho_numa_perspectiva_historica.pdf $>$. Acesso em: 21 fev. 2015.

LESSA, S. Centralidade do trabalho: qual centralidade, qual trabalho? In:

\section{Mundo}

dos homens: Trabalho e ser social. $3^{\mathrm{a}}$ edição - revista e corrigida. São Paulo: Instituto Lukács, 2012. p. 25-42.

MARX, K. Processo de trabalho e processo de produzir mais-valia. In: . O Capital:

crítica da economia política. Tradução: Reginaldo Sant'Anna. 28. ed. Rio de Janeiro:

Civilização Brasileira, 2011.

ROMANELLI, O. de O. História da educação no Brasil: (1930/1973). 36. Ed. Petrópolis: Vozes, 2010. 